\title{
Impact of timing on major complications after thoracic endovascular aortic repair for acute type $B$ aortic dissection
}

\author{
Nimesh D. Desai, MD, PhD, ${ }^{\mathrm{a}, \mathrm{b}}$ Jean-Paul Gottret, MD, ${ }^{\mathrm{b}}$ Wilson Y. Szeto, MD, ${ }^{\mathrm{b}}$ Fenton McCarthy, MD, ${ }^{\mathrm{a}, \mathrm{b}}$ \\ Patrick Moeller, BS, ${ }^{\mathrm{b}}$ Rohan Menon, BS, ${ }^{\mathrm{b}}$ Benjamin Jackson, MD, ${ }^{\mathrm{c}}$ Prashanth Vallabhajosyula, MD, ${ }^{\mathrm{b}}$ \\ Grace J. Wang, MD, ${ }^{c}$ Ronald Fairman, $\mathrm{MD},{ }^{\mathrm{c}}$ and Joseph E. Bavaria, $\mathrm{MD}^{\mathrm{b}}$
}

\begin{abstract}
Objective: Thoracic endovascular aortic repair (TEVAR) has been shown to have survival benefit in patients with complicated type B dissection compared with open surgery or medical therapy. We analyze the impact of timing of intervention from the onset of symptoms to TEVAR, and its relation to complications.
\end{abstract} Methods: Between 2005 and 2012, we performed 132 TEVARs for acute and subacute $(<6$ weeks) type B
dissection; 186 other patients were managed with medical therapy only. Patients were followed in a clinical
registry. Standard univariate and survival methods were used.

Results: Of the 132 TEVARs for type B dissection, 70 were performed within 48 hours of presentation (AcuteEarly); 44 between 48 hours and 14 days from presentation (Acute-Delayed); and 18 between 14 days and 6 weeks of presentation (Subacute). Demographic characteristics were similar among groups. Severe complications were more common in the Early-Acute and Delayed-Acute patients than in the Subacute patients $(P=.04)$ Retrograde type A dissection tended to be more common in the Acute-Early group. Overall survival was similar among groups.

Conclusions: Delayed intervention appears to lower the risk of complications of TEVAR for aortic dissection in patients who are stable enough to wait. Among patients initially managed medically, new TEVAR indications were not uncommon, and such patients must be followed closely. (J Thorac Cardiovasc Surg 2015;149:S151-6)

See related commentary on pages S156-7.

Thoracic endovascular aortic repair (TEVAR) has revolutionized the treatment of thoracic aortic diseases. TEVAR in the current era has become the dominant treatment for descending thoracic aortic aneurysms with appropriate anatomy, after the first commercial device gained US Food and Drug Administration (FDA) approval for this indication in $2005.1,2$ Subsequently, TEVAR has been used extensively

From the Leonard Davis Institute of Health Economics, ${ }^{a}$ and Divisions of Cardiovascular Surgery ${ }^{\mathrm{b}}$ and Vascular Surgery, ${ }^{\mathrm{c}}$ Perelman School of Medicine, University of Pennsylvania, Philadelphia, Pa.

Disclosures: N.D.D. reports consulting fees from Gore and Medtronic. W.Y.S. reports consulting fees from Bolton Medical and Medtronic. N.D.D., W.Y.S., J.E.B., B.J., P.V., G.J.W., and R.F. are investigators for Medtronic, Gore, and Cook Dissection Trials. J.E.B. is National Principal Investigator in the Medtronic Dissection Trial. All other authors have nothing to disclose with regard to commercial support.

Read at The American Association for Thoracic Surgery Aortic Symposium, New York, New York, April 24-25, 2014.

Received for publication July 22, 2014; revisions received Oct 22, 2014; accepted for publication Oct 26, 2014; available ahead of print Nov 25, 2014.

Address for reprints: Nimesh D. Desai, MD, PhD, Division of Cardiovascular Surgery, Perelman School of Medicine, University of Pennsylvania, 3400 Spruce St, 6 Silverstein, Philadelphia, PA 19104 (E-mail: Nimesh.Desai@uphs.upenn.edu). $0022-5223 / \$ 36.00$

Copyright $(2015$ Published by Elsevier Inc. on behalf of The American Association for Thoracic Surgery

http://dx.doi.org/10.1016/j.jtcvs.2014.10.105 for treatment of penetrating atherosclerotic ulcers, traumatic transection, and acute, complicated, type B aortic dissection.

First reported by Nienaber and colleagues, ${ }^{3}$ Moon and colleagues, ${ }^{4}$ and Dake and colleagues, ${ }^{5}$ TEVAR has become the dominant treatment of acute type B dissection complicated by either severe end-organ malperfusion or rupture. Initial studies by Szeto and colleagues ${ }^{6}$ and others $^{7-9}$ showed a dramatic decrease in early mortality when TEVAR was used in these circumstances versus open surgery. More recently, TEVAR has been proposed to prevent late distal aneurysmal degeneration from descending aortic dissection, by promoting remodeling and false lumen thrombosis. Over time, indications for TEVAR have expanded from the most dire rupture and malperfusion cases, to those with isolated renal malperfusion or severe true lumen compression without overt compromise of the distal organ function. Data from the Investigation of Stent Grafts in Aortic Dissection (INSTEAD) trial suggested that, in terms of late mortality and freedom from aortic events, in uncomplicated type B dissection patients treated within the early chronic period, TEVAR may be superior to medical therapy alone. ${ }^{10,11}$ This strategy, however, exposes the patient to significant early risks, including stroke, paralysis, and retrograde extension of the dissection. ${ }^{12}$ Anecdotally, these complications are believed to be more frequent in the early period after dissection, when the aorta is acutely inflamed and more vulnerable to mechanical complications. In the current 


\section{Abbreviations and Acronyms \\ FDA $\quad=$ US Food and Drug \\ Administration \\ INSTEAD trial $=$ Investigation of Stent Grafts in Aortic Dissection trial \\ TEVAR $=$ thoracic endovascular aortic repair}

study, we analyze the impact of the timing of intervention, from the onset of dissection symptoms to the TEVAR procedure, on the rate of complications in a group of patients undergoing TEVAR for primary clinical indications, ie, not solely for remodeling.

\section{METHODS \\ Patients}

Between 2005 and 2012, there were 317 acute type B dissection admissions at the University of Pennsylvania Health system. Among these, we performed 132 TEVARs within the acute and subacute period ( $<6$ weeks) of type B dissection. We classified the TEVAR patients into those who were stented in: the Acute-Early period (TEVAR within 48 hours of symptom onset); the Acute-Delayed period (TEVAR 48 hours to 2 weeks from symptom onset); and the Subacute period (TEVAR 2-6 weeks after symptom onset). TEVARs performed after 6 weeks from symptom onset were not included in this analysis.

Rupture seen on computed tomography imaging with hemodynamic compromise was classified as frank rupture; rupture without hemodynamic instability was classified as contained rupture. Severe ongoing pain, despite maximal blood pressure control, was defined as impending rupture. Clinical malperfusion was defined as compromise of flow into distal arterial beds from the dissection process, leading to visceral organ-threatening or limb-threatening ischemia. Single-kidney malperfusion without acute renal failure was not included in this definition. Radiographic malperfusion was defined as either a severely compressed true lumen in the aorta without end-organ or limb compromise or single-kidney malperfusion only.

\section{Surgical Approach}

Patients were triaged upon referral from emergency departments, either to direct admission to the operating room, for patients with immediate life-threatening complications, or to the intensive-care unit for initial stabilization. The TEVAR team is an interdisciplinary team of cardiac and vascular surgeons, cardiovascular anesthesiologists, neurologists, and radiologists. TEVAR procedures are performed in the hybrid operating room with highquality fixed fluoroscopy equipment. All dissection TEVARs are performed with intravascular ultrasound to verify wire position in the true lumen. Selected graft sizes are typically within $10 \%$ oversizing to the maximal outer dimension of the nondissected aorta in the proximal landing zone.

Rupture cases have total thoracic aortic coverage from the proximal to the subclavian to the celiac artery origin. Malperfusion cases are typically initially treated with a TEVAR graft $15-20 \mathrm{~cm}$ in length, and malperfusion is reassessed angiographically. If the malperfusion persists, the TEVAR is extended down to the celiac artery; if it continues to persist, adjunctive branch-graft stenting is performed. The TEVARs performed in this study were primarily done "off-label," with devices approved for aneurysm indication in the early era, followed by cases enrolled in FDA Investigation Device Exemption clinical trials assessing TEVAR in acute, complicated, type B dissection. Within the last year of the study, devices approved for dissection were used.

\section{Data and Statistical Methods}

Patients were followed in a prospectively collected clinical perioperative registry, and long-term outcomes were determined from clinical records and administrative data sources. The institutional review board at the study institution approved the study, and the need for patient consent was waived. Continuous data are presented as median \pm standard deviation; categoric variables are given as counts and percentages. For comparison of continuous variables, the Student $t$ test was used. Categoric variables were compared using $\chi^{2}$ analysis or the Fisher exact test, as appropriate. Survival was analyzed using the Kaplan-Meier method and $\log$ rank calculations.

\section{RESULTS}

Among the 132 TEVARs for type B dissection, 70 were performed within 48 hours of presentation (Acute-Early); 44 were performed between 48 hours and 14 days from initial presentation (Acute-Delayed); 18 were performed 14 days to 6 weeks after initial presentation (Subacute). The mean age of the patients was similar among groups. The majority of patients were men with a history of hypertension and frequent smoking. Table 1 shows patient characteristics.

Among the TEVARs performed in the Acute-Early group (within 48 hours of symptom onset), more than half were for rupture indications, and the majority of the remaining indications were for clinical malperfusion (Figure 1). Among the Acute-Delayed group, 12 patients $(27.3 \%)$ had new or worsening clinical malperfusion, of which 6 had worsening renal malperfusion with acute renal failure. A further 23 patients were stented for either ongoing pain/impending rupture $(12 ; 27 \%)$ or contained rupture $(11 ; 25 \%)$. Nine patients $(21 \%)$ underwent TEVAR for radiographic malperfusion with severely compressed true lumen without end-organ involvement or isolated single-kidney malperfusion without renal failure (ie, remodeling indications). Among patients in the Subacute group $(\mathrm{n}=18), 13$ $(72 \%)$ were stented after readmission for symptoms, or blood pressure control. Among these, $11 \%$ had new clinical malperfusion, $56 \%$ had impending rupture/persistent pain, and $11 \%$ had rupture. A further $22 \%$ had radiographic malperfusion and were stented for remodeling indications.

Perioperative details are presented in Table 2. Total coverage of the left subclavian artery, with no residual antegrade flow into that artery, was required in $40 \%-50 \%$ of cases. Among these, 6 patients $(9.1 \%)$ in the Acute-Early intervention group underwent carotid-subclavian bypass after the TEVAR procedure for ischemic symptoms. In the Acute-Delayed group, 4 patients $(9.4 \%)$ underwent preemptive carotid-subclavian bypass, and a larger proportion of the Subacute patient group $(5 ; 27.3 \%)$ underwent carotid-subclavian bypass before the TEVAR procedure. Typically, a median of 2 TEVAR grafts were deployed, for coverage between $253.7 \mathrm{~mm}$ and $297.8 \mathrm{~mm}$ of total coverage.

There were 2 intraoperative deaths, 1 from free aortic rupture that could not be salvaged with TEVAR (AcuteDelayed), and 1 with severe gastrointestinal malperfusion 
TABLE 1. Patient demographics and cause of TEVAR intervention

\begin{tabular}{|c|c|c|c|c|c|c|c|}
\hline & \multicolumn{2}{|c|}{$\begin{array}{l}\text { Acute-Early intervention } \\
\qquad(\mathbf{N}=\mathbf{7 0})\end{array}$} & \multicolumn{2}{|c|}{$\begin{array}{l}\text { Acute-Delayed intervention } \\
\qquad(\mathrm{N}=\mathbf{4 4 )}\end{array}$} & \multicolumn{2}{|c|}{$\begin{array}{l}\text { Subacute intervention } \\
\qquad(\mathbf{N}=\mathbf{1 8})\end{array}$} & \multirow[b]{2}{*}{$P$ value } \\
\hline & $\%$ & $\mathbf{n}$ & $\%$ & $\mathbf{n}$ & $\%$ & $\mathbf{n}$ & \\
\hline \multicolumn{8}{|l|}{ Patient demographics } \\
\hline Age $(y ;$ mean $)$ & 63.9 & SD 12.8 & 64.3 & SD 14.3 & 64.1 & SD 14.8 & .98 \\
\hline Sex (male) & 60.0 & 42 & 59.1 & 26 & 66.7 & 12 & .61 \\
\hline Cigarette smoker & 44.3 & 31 & 50.0 & 22 & 66.7 & 12 & .13 \\
\hline Prior CVA & 8.6 & 6 & 13.6 & 6 & 16.7 & 3 & .43 \\
\hline Diabetes & 12.9 & 9 & 20.5 & 9 & 11.1 & 2 & 1 \\
\hline Hypertension & 91.4 & 64 & 97.7 & 43 & 100.0 & 18 & .35 \\
\hline CKD & 14.3 & 10 & 22.7 & 10 & 33.3 & 6 & .61 \\
\hline \multicolumn{8}{|c|}{ Indication for TEVAR intervention } \\
\hline Frank rupture & 9.0 & 6 & 0.0 & 0 & 0.0 & 0 & .4 \\
\hline Contained rupture & 43.3 & 30 & 25.0 & 11 & 11.1 & 2 & .028 \\
\hline Impending rupture & 4.5 & 3 & 27.3 & 12 & 55.6 & 10 & .0002 \\
\hline Clinical malperfusion & 34.3 & 24 & 27.3 & 12 & 11.1 & 2 & .058 \\
\hline Rad. malperfusion & 1.5 & 1 & 20.5 & 9 & 22.2 & 4 & .1 \\
\hline Other & 7.5 & 5 & 0.0 & 0 & 0.0 & 0 & .47 \\
\hline
\end{tabular}

$P$ values are for the Subacute group versus the Acute-Early and Acute-Delayed groups combined. TEVAR, Thoracic endovascular aortic repair; SD, standard deviation; $C V A$, cerebrovascular accident; $C K D$, chronic kidney disease; Rad., radiographic.

and necrosis with unremitting acidosis and cardiac arrest (Acute-Early). Overall, $6(8.5 \%)$ in-hospital mortalities occurred in the Acute-Early group, $2(4.5 \%)$ in the Acute-Delayed group, and none in the Subacute group; overall $P=.26$. Permanent paralysis or severe paraparesis and permanent stroke were fairly uncommon in these patients. Retrograde aortic dissection was observed in 6 Acute-Early patients $(8.5 \%)$, and in 3 Acute-Delayed patients $(6.8 \%)$. In a single patient in the Subacute group, a retrograde type A dissection occurred, after a repeat TEVAR performed in the subacute period for proximal pseudoaneurysm; the patient had been previously stented in the early-acute period for clinical malperfusion with complex arch anatomy. The overall rate of major complications (death, permanent paralysis, permanent stroke, renal failure, and retrograde dissection) was 27 Acute-Early patients $(38.7 \%), 12$ Acute-Delayed patients $(27.3 \%)$, and 1 Subacute patient $(5.6 \%) ; P=.04$ for all acute versus subacute patients (Table 3). No overall difference was found in late survival among groups $(\log$ rank $P=.5$; Figure 2).

\section{DISCUSSION}

Treatment with TEVAR for acute, type B, aortic dissections, accompanied by life- or limb-threatening malperfusion or rupture, is well established and is associated with

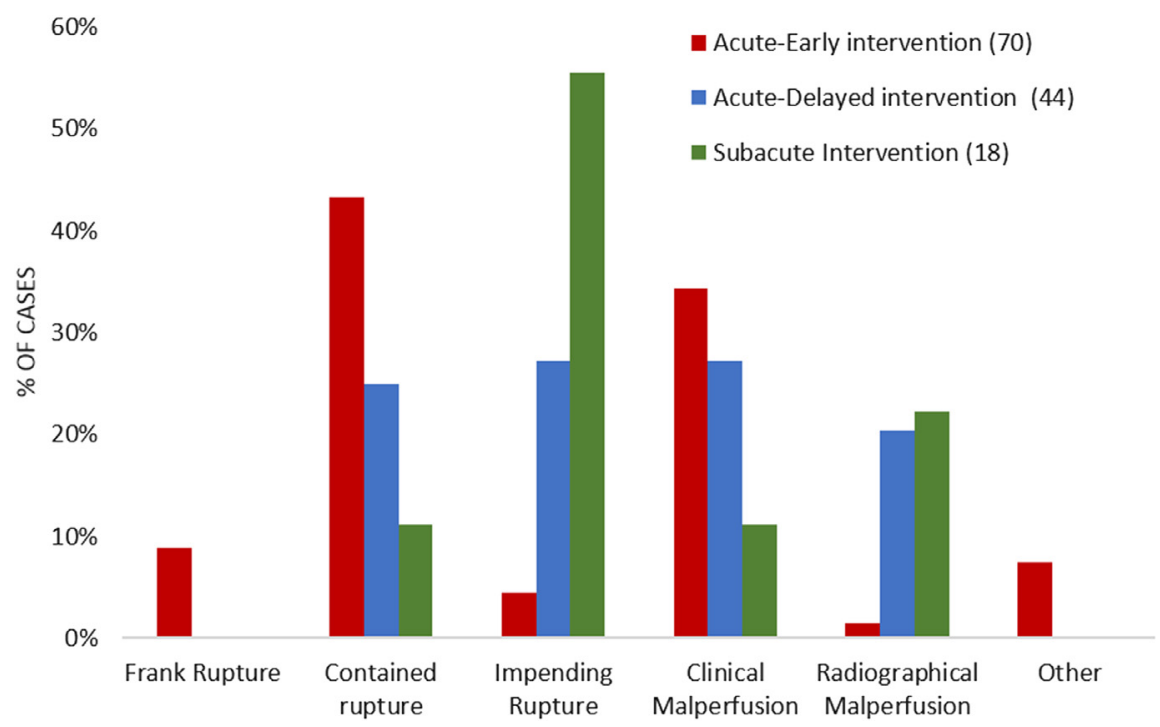

FIGURE 1. Thoracic endovascular aortic repair indication according to timing from symptom onset. 
TABLE 2. Periprocedural details

\begin{tabular}{|c|c|c|c|c|c|c|c|}
\hline \multirow[b]{2}{*}{ Procedure detail } & \multicolumn{2}{|c|}{$\begin{array}{l}\text { Acute-Early intervention } \\
\qquad(\mathbf{N}=\mathbf{7 0}) \\
\end{array}$} & \multicolumn{2}{|c|}{$\begin{array}{l}\text { Acute-Delayed intervention } \\
\qquad(\mathrm{N}=\mathbf{4 4}) \\
\end{array}$} & \multicolumn{2}{|c|}{$\begin{array}{c}\text { Subacute intervention } \\
(\mathbf{N}=\mathbf{1 8}) \\
\end{array}$} & \multirow[b]{2}{*}{$P$ valu } \\
\hline & $\%$ & $\mathbf{n}$ & $\%$ & n & $\%$ & $\mathbf{n}$ & \\
\hline LSCA coverage & 40.0 & 28 & 45.5 & 20 & 50.0 & 9 & .35 \\
\hline Left carotid subclavian bypass & $9.1^{*}$ & 6 & 9.4 & 4 & 27.8 & 5 & .017 \\
\hline Total graft length $(\mathrm{cm})$ & 253.7 & (SD 163.6) & 297.8 & (SD 113.8) & 278.4 & $(\mathrm{SD} 155.9)$ & .88 \\
\hline Number of stents implanted (median) & 2 & $(1-4)$ & 2 & $(1-4)$ & 2 & $(1-5)$ & 1 \\
\hline Vascular complication & 0.0 & 0 & 0.0 & 0 & 0.0 & 0 & .86 \\
\hline Prosthesis migration & 0.0 & 0 & 2.7 & 1 & 0.0 & 0 & .86 \\
\hline Intraoperative mortality & 1.4 & 1 & 2.3 & 1 & 0.0 & 0 & .35 \\
\hline
\end{tabular}

$P$ values are for LSCA bypass performed after thoracic endovascular aortic repair. $L S C A$, Left subclavian artery; $S D$, standard deviation. *For the Subacute group versus the Acute-Early and Acute-Delayed groups combined.

improved outcomes compared with medical or surgical treatment modalities. FDA Investigation Device Exemption studies were recently completed on 2 TEVAR devices that previously were labeled for thoracic aortic aneurysm indications for their use in acute, complicated, type B aortic dissection. ${ }^{13,14}$ Based on these studies, these grafts were approved for treatment of all descending thoracic aortic dissections-complicated or uncomplicated and acute or chronic.

Among patients with uncomplicated dissections who are managed medically, there is a $15 \%$ to $30 \%$, 5year mortality rate, predominantly from late aortic complications. ${ }^{15}$ TEVAR has been proposed as a means to prevent these late complications, via positive remodeling of the aorta. This goal is accomplished by covering the primary entry tear and thrombosing at least the covered portion of the false lumen, which may prevent late dilatation.

Nienaber and colleagues ${ }^{11}$ recently reported results of the INSTEAD trial, in which patients with de novo type B dissection were randomized either to TEVAR, with the first-generation Talent TEVAR graft (Medtronic, Inc, Minneapolis, Minn) plus optimal medical therapy, or to optimal medical therapy alone. ${ }^{11}$ The early results of this study showed improved remodeling of the aorta at the potential cost of elevated early clinical complications. At 5 years, event-free survival was better in the TEVAR arm of the trial, and significant interest has evolved in performing TEVAR for this indication. ${ }^{10}$

Despite increasing use of TEVAR in acute type B aortic dissection, there is a paucity of data on periprocedural complications and the relative impact of timing of intervention on their occurrence. To date, no clear guidance is available on optimal timing of TEVAR in the uncomplicated acute dissection patient. Earlier intervention is potentially advantageous, as the dissection flap is most pliable and provides the best chance for complete remodeling. This advantage must be balanced with the potential increased risks of damage to the acutely inflamed aorta, by either the wires or the stent-graft, which may predispose the patient to retrograde dissection. In the INSTEAD trial, patients were typically treated at more than 60 days after initial dissection, and the rate of technical complications was very low. The aorta was successfully remodeled in the large majority of cases that were randomized to TEVAR, indicating that even this long after initial dissection,

TABLE 3. Perioperative outcomes

\begin{tabular}{|c|c|c|c|c|c|c|c|}
\hline \multirow[b]{2}{*}{ Outcome } & \multicolumn{2}{|c|}{$\begin{array}{l}\text { Acute-Early intervention } \\
(\mathbf{N}=\mathbf{7 0}) \\
\end{array}$} & \multicolumn{2}{|c|}{$\begin{array}{l}\text { Acute-Delayed intervention } \\
\qquad(\mathrm{N}=44) \\
\end{array}$} & \multicolumn{2}{|c|}{ Subacute intervention (18) } & \multirow[b]{2}{*}{$P$ value } \\
\hline & $\%$ & $\mathbf{n}$ & $\%$ & $\mathbf{n}$ & $\%$ & n & \\
\hline In-hospital mortality & 8.6 & 6 & 4.5 & 2 & 0 & 0 & .28 \\
\hline Mortality at $30 \mathrm{~d}$ & 12.7 & 9 & 6.8 & 3 & 0 & 0 & .14 \\
\hline Any paralysis & 7.0 & 5 & 4.5 & 2 & 11.1 & 2 & 1 \\
\hline Paralysis (permanent) & 1.4 & 1 & 2.2 & 1 & 5.6 & 1 & 6 \\
\hline Any stroke & 5.6 & 4 & 4.6 & 2 & 0 & 0 & .68 \\
\hline Stroke (permanent) & 1.4 & 1 & 2.3 & 1 & 0 & 0 & 1 \\
\hline New renal failure & 8.5 & 6 & 6.8 & 3 & 0 & 0 & .5 \\
\hline Retrograde type A dissection & 8.5 & 6 & 6.8 & 3 & $0^{*}$ & 0 & $.5 \dagger$ \\
\hline Overall major complication & 38.7 & 27 & 27.3 & 12 & 5.6 & 1 & .04 \\
\hline
\end{tabular}

*Retrograde Type A dissection occurred in a repeat TEVAR performed in the subacute period for a proximal type 1 endoleak in a patient previously stented for clinical malperfusion with complex arch anatomy. This was excluded, as it was from a repeat TEVAR procedure. †For the Subacute group versus the Acute-Early and Acute-Delayed groups combined. 


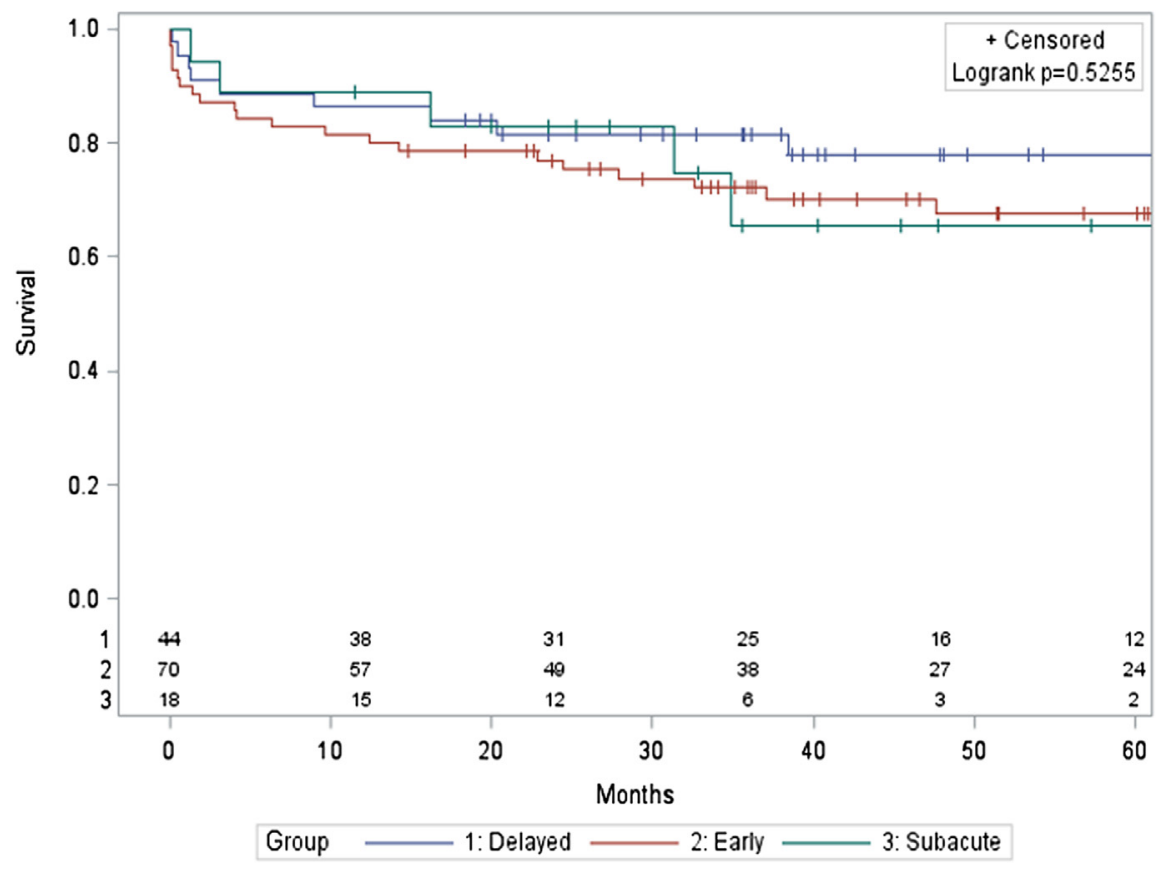

FIGURE 2. Long-term survival stratified by timing of intervention.

the dissection flap is still mobile, and a proximal seal can still be achieved. ${ }^{11}$

In the current study, we found a relationship between earlier intervention and increased periprocedural complications. Among these were a numerically greater number of deaths, acute kidney injury, neurologic complications, and retrograde dissections in patients who underwent previous interventions. The composite outcome incorporating these meaningful clinical endpoints reached significance. These patients were typically implanted with a stentgraft for clinical reasons, and not solely for aortic remodeling, although this was a more common indication in the subacute patients. The overall rate of these complications in the earlier intervention phases warrants close examination, as they provide guidance regarding potential risks associated with early TEVAR for type B dissection. As many patients in the Delayed-Acute and Subacute groups developed new Early-Acute type indications, acuity and complication rates in these groups are likely overestimated; thus, we would expect elective TEVAR for solely remodeling purposes to have even lower complication rates. This effect may be more pronounced in the AcuteEarly group, who were more frequently patients with immediate life-threatening complications from type B dissection.

The development of new TEVAR indications in the initially medically managed subgroups (Acute-Delayed and Subacute) provides new insight into the fate of medically managed type B dissection patients, and stresses the importance of routine follow-up and close surveillance. In the later years of the study, we developed a process at our center for early telephone follow-up by a nurse navigator, an approach that has helped identify patients with evolving dissection-related problems before an aortic catastrophe occurred.

Retrograde dissection was observed in 9 of 132 patients $(6.8 \%)$ in this study. This rate is similar to that of retrograde dissection observed in the preapproval acute, complicated, dissection trials using the Valiant Captivia stent graft (Medtronic, Inc, Minneapolis, Minn) (2 of 50; 5\% at 1 year) and the conformable GORE TAG thoracic endoprosthesis device (W. L. Gore \& Associates, Inc, Flagstaff, Ariz) (5 of $50 ; 10 \%$ at 1 year). In our study, 2 retrograde dissections occurred more than 1 year after implant, and the 1-year rate of retrograde dissection was 7 of $132(5.5 \%)$. Given that this was an "all-comers" series, patients with poor proximal landing-zone features, such as thrombus/intramural hematoma or severe angulation, were included; these patients would have been excluded from the FDA studies. We only included patients with true retrograde dissection in this study, ie, situations in which the stent graft caused the primary aortic tear.

In summary, earlier intervention with TEVAR is associated with increased postprocedural complications, and the risk of these complications diminished over time, even when the TEVAR was performed for new lifethreating indications. Our practice has developed an approach of waiting 2 weeks or longer to perform TEVAR in patients, if it is solely for remodeling purposes. The safety of delayed TEVAR for remodeling purposes 
warrants further investigation, with multicenter randomized clinical trials.

\section{References}

1. Bavaria JE, Appoo JJ, Makaroun MS, Verter J, Yu ZF, Mitchell RS, Gore TAG Investigators. Endovascular stent grafting versus open surgical repair of descending thoracic aortic aneurysms in low-risk patients: a multicenter comparative trial. J Thorac Cardiovasc Surg. 2007;133:369-77.

2. Makaroun MS, Dillavou ED, Kee ST, Sicard G, Chaikof E, Bavaria J, et al. Endovascular treatment of thoracic aortic aneurysms: results of the phase II multicenter trial of the GORE TAG thoracic endoprosthesis. J Vasc Surg. 2005;41:1-9.

3. Nienaber CA, Fattori R, Lund G, Dieckmann C, Wolf W, von Kodolitsch Y, et al. Nonsurgical reconstruction of thoracic aortic dissection by stent-graft placement. N Engl J Med. 1999;340:1539-45.

4. Moon MR, Dake MD, Pelc LR, Liddell R, Castro LJ, Mitchell RS, et al. Intravascular stenting of acute experimental type B dissections. J Surg Res. 1993;54: 381-8.

5. Dake MD, Miller DC, Semba CP, Mitchell RS, Walker PJ, Liddell RP. Transluminal placement of endovascular stent-grafts for the treatment of descending thoracic aortic aneurysms. N Engl J Med. 1994;331:1729-34.

6. Szeto WY, McGarvey M, Pochettino A, Moser GW, Hoboken A, Cornelius K, et al. Results of a new surgical paradigm: endovascular repair for acute complicated type B aortic dissection. Ann Thorac Surg. 2008;86:87-93.

7. Zeeshan A, Woo EY, Bavaria JE, Fairman RM, Desai ND, Pochettino A, et al, Thoracic endovascular aortic repair for acute complicated type B aortic dissection: superiority relative to conventional open surgical and medical therapy. J Thorac Cardiovasc Surg. 2010;140(6 Suppl):S109-15.
8. Verhoye JP, Miller DC, Sze D, Dake MD, Mitchell RS. Complicated acute type B aortic dissection: midterm results of emergency endovascular stent-grafting. J Thorac Cardiovasc Surg. 2008;136:424-30.

9. Pearce BJ, Passman MA, Patterson MA, Taylor SM, Lecroy CJ, Combs BR, et al. Early outcomes of thoracic endovascular stent-graft repair for acute complicated type B dissection using the Gore TAG endoprosthesis. Ann Vasc Surg. 2008;22: 742-9.

10. Nienaber CA, Rousseau H, Eggebrecht H, Kische S, Fattori R, Rehders TC, et al Randomized comparison of strategies for type B aortic dissection: the INvestigation of STEnt Grafts in Aortic Dissection (INSTEAD) trial. Circulation. 2009; 120:2519-28.

11. Nienaber CA, Kische S, Rousseau H, Eggebrecht H, Rehders TC, Kundt G, et al. Endovascular repair of type B aortic dissection: long-term results of the randomized investigation of stent grafts in aortic dissection trial. Circ Cardiovasc Interv. 2013;6:407-16.

12. Neuhauser B, Greiner A, Jaschke W, Chemelli A, Fraedrich G. Serious complications following endovascular thoracic aortic stent-graft repair for type B dissection. Eur J Cardiothorac Surg. 2008;33:58-63.

13. Bavaria J, Brinkman W, Hughes GC, Khoynezad A, Szeto WY, Azizzadeh A, et al. Outcomes of TEVAR in acute type B aortic dissection: results from the Valiant US-IDE Study. Ann Thorac Surg. (in press).

14. W.L. Gore and Associates. Evaluation of the GORE Conformable TAG ${ }^{\circledR}$ Thoracic Endoprosthesis for treatment of acute complicated type B aortic dissection. Available at: http://clinicaltrials.gov/ct2/show/study/NCT00908388?sect= X870156. Accessed September 14, 2014.

15. Fattori R, Montgomery D, Lovato L, Kische S, Di Eusanio M, Ince H, et al. Survival after endovascular therapy in patients with type B aortic dissection: a report from the International Registry of Acute Aortic Dissection (IRAD). JACC Cardiovasc Interv. 2013;6:876-82.

\section{EDITORIAL COMMENTARY}

\section{Timing in life is everything}

Ali Khoynezhad, MD, PhD

See related article on pages S151-6.

Complicated acute type B aortic dissection (cTBAD) is one of most challenging clinical scenarios encountered in clinical practice of cardiovascular surgeons. Technical aspects and outcomes associated with open repair have been challenging. Thoracic endovascular repair (TEVAR) has resulted in at least $50 \%$ reductions in mortality and neurologic complications relative to open repair. ${ }^{1}$ The aortic surgical community has therefore recommended a change of paradigm to

From the Division of Cardiothoracic Surgery, Cedars-Sinai Medical Center, Los Angeles, Calif.

Disclosures: Author has nothing to disclose with regard to commercial support.

Received for publication Nov 3, 2014; accepted for publication Nov 4, 2014; available ahead of print Dec 4, 2014.

Address for reprints: Ali Khoynezhad, MD, PhD, Division of Cardiothoracic Surgery, Cedars-Sinai Medical Center, 127 S San Vicente Blvd, Suite A3306, Los Angeles, CA 90048 (E-mail: akhoy@cshs.org).

J Thorac Cardiovasc Surg 2015;149:S156-7

$0022-5223 / \$ 36.00$

Copyright (C) 2015 by The American Association for Thoracic Surgery

http://dx.doi.org/10.1016/j.jtcvs.2014.11.009
TEVAR as the primary approach for these patients in the last 5 years. ${ }^{2}$

In this issue of the Journal of Thoracic and Cardiovascular Surgery, Desai and coworkers ${ }^{3}$ add to the growing literature evaluating the relationship between the timing of TEVAR and disease- and procedure-related complications in patients with cTBAD. ${ }^{3}$ In this cohort, the rates of major adverse events, including death, permanent neurologic deficit, renal failure, and retrograde type A dissection, were $39.4 \%$ for patients treated within the first 2 days of symptoms, $27.3 \%$ for patients treated within 2 to 14 days, and $5.5 \%$ for those treated between 14 and 45 days, with the difference statistically significant $(P=.04)$ for all acute versus subacute cases. Now, the definition of the subacute phase in the literature is 14 days to 3 months. It is unclear to me why Desai and coworkers ${ }^{3}$ decided to exclude patients treated between 45 and 90 days. Inclusion of the entire subacute cohort out to 3 months might have changed or softened the statistical significance. Needless to say, it is highly recommended to use similar criteria for patient selection and outcome reporting as are used in the literature, so as to have apples-to-apples comparisons among studies. 